\title{
Correction to: In vitro antioxidant and anti-inflammatory activities of Melipona beecheii honey protein fractions
}

\author{
Jorge Carlos Ruiz-Ruiz ${ }^{1,3}$ • Pablo Acereto-Escoffié ${ }^{2}$. Maira Rubí Segura-Campos ${ }^{2}$
}

Published online: 9 October 2018

(c) Springer Science+Business Media, LLC, part of Springer Nature 2018

\section{Correction to: \\ Journal of Food Measurement and Characterization https://doi.org/10.1007/s11694-018-9881-6}

The original version of this article unfortunately contained error in affiliation of Dr. Jorge Carlos Ruiz-Ruiz and Acknowledgements section.

Affiliation of first author Dr. Jorge Carlos Ruiz-Ruiz should be División de Estudios de Posgrado e Investigación, Instituto Tecnológico de Mérida, Av. Tecnológico km. 4.5 S/N, C.P. 97,118, Mérida, Yucatán, México in the paper. The study described was carried out while he was under contract with that institution and was joint co-supervisor with Dr. Maira Rubí Segura Campos (Facultad de Ingeniería Química-Universidad Autónoma de Yucatán) of Ángel Jesús Matus Basto during two semesters. Universidad Anáhuac Mayab is his current affiliation.

Revised Acknowledgements content is given below.

The original article can be found online at https://doi.org/10.1007/ s11694-018-9881-6.

Maira Rubí Segura-Campos

maira.segura@correo.uady.mx

1 Escuela de Nutrición, División de Ciencias de la Salud, Universidad Anáhuac-Mayab, Mérida, Mexico

2 Facultad de Ingeniería Química, Universidad Autónoma de Yucatán, Periférico Norte. Km. 33.5, Tablaje catastral 13615 , Col. Chuburná de Hidalgo Inn, C.P. 97203 Mérida, Yucatán, Mexico

3 División de Estudios de Posgrado e Investigación, Instituto Tecnológico de Mérida, Av. Tecnológico km. 4.5 S/N, C.P. 97118 Mérida, Yucatán, Mexico
Acknowledgements The authors thank Ángel Jesús Matus Basto since this article publishes results of his unfinished thesis while he was enrolled at the Masters Program in Food Science and Biotechnology of the Tecnológico Nacional de México-Instituto Tecnológico de Mérida. The methods described and data collection were carried out at the laboratories of Facultad de Ingeniería Química-Universidad Autónoma de Yucatán. The authors also thank Dr. Elizabeth Ortiz Vázquez (Tecnológico Nacional de México-Insituto Tecnológico de Mérida) for her participation as a co-supervisor of Ángel Jesús Matus Basto with Dr. Maira Rubí Segura Campos (Facultad de Ingeniería Química-Universidad Autónoma de Yucatán) during two semesters, and Jesús Manuel Ramón Sierra for training Ángel Jesús Matus Basto in several laboratory techniques. 